\title{
A contribuição das empresas fornecedoras nas competências de uma cadeia de suprimentos do setor automotivo
}

\author{
Carina Silveira Pereira \\ Mestre em Administração pela PUCRS \\ cari@terra.com.br \\ Grace Vieira Becker \\ Professora do PPGAD da PUCRS \\ grace.becker@pucrs.br \\ Peter Bent Hansen \\ Professor do PPGAD da PUCRS \\ peter.hansen@pucrs.br

\section{Andre Gazineu} \\ Bolsista de Iniciação Científica da PUCRS \\ andre.gazineu@acad.pucrs.br
}

A partir da década de 90, em função de um processo de profundas transformações na configuração da economia, observa-se um movimento das organizações para desenvolverem estratégias empresariais buscando vantagens em ações coletivas. Dentre os modelos organizacionais que representam estes esforços, destacam-se as cadeias de suprimentos. Sob esta perspectiva, pode-se afirmar que as competências de uma cadeia são sustentadas pelo objetivo comum de produzir um produto da melhor maneira possível, dependendo, assim, sensivelmente da contribuição de cada uma das empresas que a compõem. Neste contexto, esta pesquisa buscou identificar a contribuição de empresas fornecedoras nas competências de uma cadeia de suprimentos. Caracteriza-se como uma pesquisa qualitativa, na forma de um estudo de caso em uma cadeia de suprimentos automotiva localizada no Estado do Rio Grande do Sul, Brasil. Os resultados mostraram que as empresas fornecedoras apresentam diferentes níveis de agregação de valor, mas esta diferenciação não é expressiva.

Palavras-chave: Cadeia de suprimentos, Competências, Setor Automotivo

Beginning in the 1990's, because of profound changes in the configuration of the economy, a movement of organizations to develop business strategies which seek advantages in collective action has been observed. Among these organizational models which represent these efforts, the supply chains stand out. From this perspective it can be affirmed that the competences of a chain are sustained by the common objective of producing a product in the best way possible, thus depending on the contribution of each of the businesses involved. This study seeks to identify 
the supplier's contribution to the competences of a supply chain. This is a qualitative research in the form of a case study of an automobile supply chain situated in the state of Rio Grande do Sul, Brazil. The results show that the suppliers present different levels of added value, however the differentiation is not expressive.

Keywords: supply chain, competences, automobile sector

\section{Introdução}

A partir da década de 90, em função de um processo de profundas transformações na configuração da economia, observa-se um movimento das organizações para desenvolverem estratégias empresariais buscando vantagens em ações coletivas. Isso implica em reunirem-se diferentes bases de recursos entre organizações para atender à maior demanda por soluções sistêmicas (CLEGG \& HARDY, 1998). Por envolver um conjunto de diversos tipos de competências, tais soluções dificilmente poderiam ser desenvolvidas por uma organização atuando de forma isolada ou auto-suficiente no mercado (PARKE, 1998). Entre os modelos organizacionais que representam estes esforços conjuntos entre empresas, destacam-se as cadeias de suprimentos.

A cadeia de suprimentos consiste numa rede de empresas que trabalham em conjunto em diferentes processos para produzir valor, apresentando-se como um elo que permite ligar o mercado, compras, produção e distribuição (BALLOU, GILBERT \& MUKHERJEE, 2000; LAMBERT, COOPER \& PAGH, 1998). Pode-se afirmar que as competências organizacionais de uma cadeia de suprimentos são sustentadas por um objetivo comum de produzir um produto/serviço da melhor maneira possível (STIJNEN, GRAAFF \& ROEST, 1998; TEIXEIRA \& LACERDA, 2010), dependendo, assim, sensivelmente da contribuição de cada uma das empresas que a compõe.

As cadeias são formadas por diferentes empresas. No caso aqui analisado, uma cadeia de suprimentos automotiva localizada no Rio Grande do Sul, encontrase diversos fornecedores atuando conjuntamente, coordenados pela empresa focal. Existem os fornecedores instalados dentro do condomínio industrial e também os fornecedores instalados na capital e região metropolitana de Porto Alegre. Todos estes fornecedores possuem características e culturas próprias advindas das suas origens e de seus idealizadores. Fornecem distintos suprimentos, tais como peças e componentes, módulos e sistemas completos para a cadeia em diferentes escalas de quantidade, de tempo e seqüência. Nesta união de diferentes características e peculiaridades organizacionais, cada empresa fornecedora pode responder de forma distinta aos resultados esperados pela empresa focal, ou seja, traduzindo resultados esperados pela cadeia em níveis distintos. Sob esta perspectiva e tendo em vista que as organizações competem no mercado por complexidade, ou seja, pelo nível de agregação de valor de suas competências organizacionais (BECKER, 2004; VINHAS, 2008), entende-se que existem níveis distintos de agregação de valor das empresas fornecedoras em relação às competências da cadeia de que participam. Visando trazer novas abordagens prático-teóricas que acrescentem reflexões acerca do tema, este trabalho tem como objetivo analisar a contribuição de oito empresas fornecedoras, sob a perspectiva dos níveis de agregação de valor, nas competências de uma cadeia de suprimentos automotiva. Entende-se que ao se 
explicitar estes níveis de contribuição, as empresas fornecedoras possam ajustar suas atribuições e responsabilidades e, através de ações, produzirem os resultados esperados pela cadeia. Assim, as empresas fornecedoras podem tomar uma posição pró-ativa no sentido de potencializar a sua contribuição na agregação de valor das competências organizacionais da cadeia de suprimentos em que estão inseridas.

\section{Cadeias de suprimentos, competências organizacionais e agregação de valor}

O modelo de gestão onde a empresa produzia sozinha todos ou quase todos os recursos necessários para o atendimento da sua demanda tornou-se inviável (PARKHE, 1998). Poucas empresas continuam verticalmente integradas, pois se tornam mais focadas, especializadas e buscam fornecedores que assumam um papel de parceiros, oferecendo confiabilidade e qualidade.

Esta tendência, caracterizada por um movimento de eliminação das fronteiras que limitam as organizações, comprova-se na medida em que elas se fundem e se aglomeram, formando cadeias, conglomerados, redes e alianças, dando origem a ações coletivas por meio de atividades compartilhadas entre as organizações que possuem algo a contribuir (CLEGG e HARDY, 1998).

Dentro destas tipologias, destaca-se a cadeia de suprimentos. Esta pode ser considerada como uma network (rede), constituída de muitos participantes com interesses diferentes, mas com um mesmo objetivo: produzir um produto da melhor maneira possível (STIJNEN, GRAAFF e ROEST, 1998).

A cadeia de suprimentos apresenta-se no ambiente de negócios como um elo que permite ligar o mercado, a atividade de compra, o processo de produção e a rede de distribuição de tal modo que os consumidores tenham um alto nível de serviço ao menor custo total, simplificando assim o complexo processo de negócios e ganhando eficiência (BALLOU, GILBERT e MUKHERJEE, 2000).

Lummus e Vokurka (1999) definem cadeia de suprimentos como todas as atividades envolvidas na entrega de um produto, desde a matéria-prima até o consumidor, incluindo compras de materiais, fabricação, montagem, armazenagem, rastreamento de estoques, lançamento e administração de pedidos, distribuição através de todos os canais e entrega ao consumidor final. Cox, Sanderson e Watson (2001, p.28) acrescentam que a cadeia de suprimentos é como "uma rede de relacionamentos interorganizacionais que deve existir para a criação de qualquer produto ou serviço que será fornecido a um consumidor final". Segundo Lambert, Cooper e Pagh (1998), o pressuposto que resume o conceito de cadeias de suprimentos é a integração das empresas da cadeia produtiva com base nos fluxos de materiais (matérias-primas, produtos em processo e produtos acabados) e informações. Assume-se, na presente pesquisa, que a cadeia de suprimentos engloba todas as atividades e processos necessários para comprar, planejar, produzir, vender e entregar ao consumidor final, um produto ou serviço com integridade que atenda as suas necessidades e expectativas (LAMBERT, COOPER e PAGH, 1998; LUMMUS e VOKURKA, 1999; COX, SANDERSON e WATSON, 2001 e FURLANETTO, 2002).

A estrutura empresarial de uma cadeia de suprimentos pode situar-se dentro de um condomínio industrial. Os condomínios industriais destacam-se atualmente na 
indústria automobilística como um conjunto de fornecedores que são convidados ou pressionados, conforme o poder de negociação exercido pela empresa focal, para estabelecer suas instalações dentro da planta e passam a fornecer componentes ou subconjuntos completos (AMATO NETO e D'ANGELO, 2005). Para Lambert e Cooper (2000), a empresa focal é aquela a partir da qual a cadeia de suprimentos é analisada, tanto nas ligações com os fornecedores, quanto com os clientes. Os fornecedores localizados dentro de um condomínio industrial automotivo, segundo os Amato Neto e D'Angelo (2005), adquiriram uma nova formatação, pois são identificados como fornecedores sistemistas. Um fornecedor sistemista é uma empresa instalada dentro do condomínio industrial que divide os custos de infraestrutura, transporte, saúde, alimentação, entre outros serviços, possuem um relacionamento estreito com a empresa focal e são responsáveis pela industrialização de um importante sistema do automóvel.

Autores como Chopra e Meindl (2003) definem que o objetivo de toda cadeia de suprimentos é maximizar o valor geral gerado, através de ganhos de receita ou redução de custos, tempos, desperdícios, etc. $O$ valor gerado por uma cadeia de suprimentos se dá através da diferença entre o valor do produto final para o cliente e o esforço realizado pela cadeia de suprimento para atender a uma demanda, um pedido.

Para maximizar o valor gerado pela cadeia de suprimentos é necessária uma ampla sincronia entre todos os processos da cadeia, transpondo de uma atitude adversativa e conflitante e migrando para atitudes de apoio, parceria e colaboração, estabelecendo um novo perfil de relacionamento entre as empresas participantes da cadeia. Conforme Lambert (2004) a parceria e colaboração entre as organizações pertencentes a uma cadeia de suprimentos é um caminho para descobrir e manter as vantagens competitivas.

Neste sentido, a presente pesquisa sugere que as competências de cadeias de suprimentos referem-se a manifestações de integração, mobilização e visão estratégica dos recursos, habilidades e capacidades disponíveis, com o propósito de agregar valor ao arranjo. Fundamentando-se nas contribuições de Ruas (1999), Fleury e Fleury (2000), Zarifian (2001) e Mills, Platts, Bourne e Richards (2002), sobre competências organizacionais e Lambert, Cooper e Pagh (1998), Lummus e Vokurka (1999), Cox, Sanderson e Watson (2001) e Furlanetto (2002) sobre cadeias de suprimentos, entende-se que as competências da cadeia são formadas a partir da integração e alinhamento estratégico dos recursos disponíveis, juntamente com a capacidade de explorá-los, tornando esta competência de grande apropriabilidade pelo arranjo e de difícil imitabilidade pelos concorrentes.

No presente trabalho, parte-se do pressuposto que, quanto maior for o grau de complexidade das ações de uma empresa, maior será sua capacidade de diferenciar-se e de adicionar valor ao mercado. Tendo como base esta perspectiva destacam-se os trabalhos de Becker (2004) e Vinhas (2008). Becker, ao analisar a trajetória de desenvolvimento de competências de uma empresa do setor automobilístico e Vinhas, ao estudar a contribuição das empresas associadas nas competências de uma rede de cooperação interorganizacional, concluíram que as organizações competem no mercado por complexidade, ou seja, pelo nível de agregação de valor de suas competências organizacionais. Esta visão é compartilhada também por Figueiredo (2001). O autor, ao realizar um estudo sobre a influência de processos de aprendizagem na trajetória de acumulação de capacidades tecnológicas em empresas na fase de industrialização, indica um 
aumento de complexidade e de agregação de valor das competências organizacionais na empresa investigada ao longo do tempo.

Com base nas considerações apresentadas, pode-se afirmar que os níveis de agregação de valor da competência, demonstram uma determinada certificação ou, mais precisamente, demonstram os diferentes graus de contribuição das empresas parceiras na competência da cadeia em cada nível de complexidade atingido. A partir da identificação das competências da cadeia, tem-se a possibilidade de caracterização dos respectivos níveis de agregação de valor desta competência.

Para tanto, acredita-se que as competências de uma cadeia de suprimentos estão alicerçadas sobre Fatores Críticos de Sucesso (FCS) onde cada FCS reúne competências organizacionais específicas para a atuação deste arranjo. Identificados então os Fatores Críticos de Sucesso em cadeias de suprimentos na literatura, partese para a investigação na cadeia de suprimento automobilística, objeto deste estudo, tendo em vista a seguinte lógica de trabalho: definição das competências desta cadeia, definição dos níveis de agregação de valor para cada competência da cadeia e, finalmente, identificação dos níveis de agregação de valor das empresas fornecedoras em relação às competências da cadeia.

\section{Fatores críticos de sucesso em cadeias de suprimento}

Os estudos acerca dos Fatores Críticos de Sucesso, em inglês Critical Success Factor, tiveram início ao final da década de 70, com o objetivo de identificar os principais fatores de sucesso para a gestão empresarial (Torres, 1989). O termo é definido por Rockart (1979) como "elementos de postura estratégica essenciais para assegurar ou melhorar a posição competitiva da empresa frente à concorrência".

Para uma cadeia de suprimentos, constituída de participantes com um mesmo objetivo, os Fatores Críticos de Sucesso são tópicos estratégicos e fundamentais para gerir a cadeia e torná-la competitiva. Diversos autores como Christopher (1997), Lummus e Vokurka (1999), Davis, Aquilano e Chase, (2001), Chopra e Meindl (2003), Lambert (2004), Eng (2006), Vieira, Yoshizaki e Ho, (2009) propõem na literatura diferentes Fatores Críticos de Sucesso para cadeias. Os FCS para estes autores são os seguintes: qualidade, serviço, custo e tempo (CHRISTOPHER, 1997); alinhar estratégias entre cadeias e organizações, assertividade nas previsões de demanda, aprimorar o relacionamento com fornecedores, desenvolver uma rede de informações clara e adotar indicadores de desempenho (LUMMUS \& VOKURKA, 1999); relacionamento com fornecedores, competitividade, tecnologia, risco reduzido ou compartilhado, confiança e compartilhamento de informações (DAVIS, AQUILANO \& CHASE, 2001); estoques, transportes instalações e informação (CHOPRA \& MEINDL, 2003), gestão das relações com os clientes, gestão do serviço ao cliente, gestão da demanda, gestão de pedidos, gestão do fluxo de produção, gestão das relações com o fornecedor, gestão do desenvolvimento e comercialização e gestão dos retornos (LAMBERT, 2004); normas de cooperação, compartilhamento de informações, compartilhamento de conhecimentos, cultura participativa e confiança mútua (ENG, 2006) e colaboração estratégica, ações conjuntas, compartilhamento de ganhos e custos, compartilhamento de informações logísticas e comerciais e colaboração interpessoal (VIEIRA, YOSHIZAKI \& HO, 2009). 
Diante deste vasto campo de discussão sobre FCS, para a realização desta pesquisa tornou-se necessário a classificação e agrupamento dos fatores críticos conforme a similaridade dos assuntos discutidos e, posteriormente, seu enquadramento em diferentes categorias. As categorias foram criadas através do agrupamento dos fatores críticos, os quais abordam no seu contexto discussões semelhantes. Para estas categorias foi dado o nome de Eixo Crítico, por entender que $o$ eixo é o elemento central de qualquer movimento. A presente pesquisa compreende que os eixos críticos, formatados a partir do agrupamento dos fatores críticos, podem ser a base para o êxito ou insucesso de uma cadeia de suprimentos. Os nove Eixos Críticos identificados a partir dos estudos mencionados são os seguintes: Relacionamento com a Cadeia, Gestão da Informação, Relacionamento com o cliente, Gestão de Materiais, Administração da Produção, Gestão de Custos, Análise de Mercado, Gestão da Qualidade e Indicadores de Performance.

Como critério, para esta escolha dos Eixos que foram investigados nesta pesquisa, utilizou-se o método da freqüência. Após a mensuração dos Eixos Críticos conforme sua freqüência de aparição, a presente pesquisa utilizou o Princípio de Pareto para elencar quais os Eixos Críticos são mais representativos para os resultados e conclusões do trabalho. O Quadro 1 apresenta nas suas linhas os nove Eixos em estudo e nas suas colunas a freqüência absoluta de cada Eixo, a freqüência absoluta acumulada, a freqüência relativa e a freqüência relativa acumulada.

\begin{tabular}{|c|c|c|c|c|}
\hline Eixos & $\begin{array}{c}\text { Freqüênc } \\
\text { ia } \\
\text { Absoluta }\end{array}$ & $\begin{array}{c}\text { Freqüênci } \\
\text { a } \\
\text { Absoluta } \\
\text { Acumulad } \\
\text { a } \\
\end{array}$ & $\begin{array}{l}\text { Freqüênci } \\
\text { a Relativa }\end{array}$ & $\begin{array}{c}\text { Freqüênci } \\
\text { a Relativa } \\
\text { Acumulad } \\
\text { a }\end{array}$ \\
\hline $\begin{array}{l}\text { Relacionamento com a } \\
\text { Cadeia }\end{array}$ & 16 & 16 & $36 \%$ & $36 \%$ \\
\hline Gestão da Informação & 7 & 23 & $16 \%$ & $51 \%$ \\
\hline $\begin{array}{l}\text { Relacionamento com o } \\
\text { Cliente }\end{array}$ & 7 & 30 & $16 \%$ & $67 \%$ \\
\hline Gestão de Materiais & 5 & 35 & $11 \%$ & $78 \%$ \\
\hline $\begin{array}{ll}\text { Administração } & \text { da } \\
\text { Produção } & \end{array}$ & 3 & 38 & $7 \%$ & $84 \%$ \\
\hline Gestão de Custos & 3 & 41 & $7 \%$ & $91 \%$ \\
\hline Análise de Mercado & 2 & 43 & $4 \%$ & $96 \%$ \\
\hline Gestão da Qualidade & 1 & 44 & $2 \%$ & $98 \%$ \\
\hline $\begin{array}{ll}\text { Indicadores } & \text { de } \\
\text { Performance } & \\
\end{array}$ & 1 & 45 & $2 \%$ & $100 \%$ \\
\hline TOTAL & 45 & & & \\
\hline
\end{tabular}

Analisando o Quadro1, pode-se observar a representatividade absoluta e percentual de cada Eixo Crítico. Pelo Princípio de Pareto a pesquisa selecionou os quatro primeiros Eixos Críticos que são: relacionamento, informação, cliente e materiais, pois estes representam, conforme sua freqüência relativa acumulada $77,78 \%$ do todo pesquisado. Desta forma, foram elaboradas as seguintes definições: 
1) Eixo Crítico Relacionamento com a Cadeia: Oportunizar a integração das atividades nos processos de negócios da cadeia, aumentando a capacidade de resposta e aprimorando as alianças estratégicas com fornecedores e parceiros, gerando confiabilidade, interdependências e compartilhamento de riscos e benefícios.

2) Eixo Crítico Gestão da Informação: Controlar e compartilhar informações críticas com confiança e agilidade, para dar visibilidade às decisões capazes de melhorar a lucratividade de toda a cadeia.

3) Eixo Crítico Relacionamento com o Cliente: Conjunto de esforços para aproximar e antever as expectativas do consumidor final, através de programas de fidelização, qualidade do produto, atendimento e serviços de pós-venda.

4) Eixo Crítico Gestão de Materiais: Controlar a sincronia entre pedido, armazenagem, níveis de estocagem, movimentação e distribuição de suprimentos ao longo de toda a cadeia.

Posto isto, o presente estudo tomará por base estes quatro eixos críticos propostos. Na seção seguinte serão apresentados os procedimentos metodológicos que darão suporte aos resultados da pesquisa.

\section{Procedimentos metodológicos}

O método de pesquisa utilizado para atender aos objetivos propostos foi o método qualitativo, através de um estudo de caso baseado principalmente em dados coletados em entrevistas. Segundo Dubé e Paré (2003) os estudos de caso são apropriados quando o objeto de investigação é complexo, sendo necessária uma visão do todo e também quando o fenômeno estudado não pode ser analisado fora do contexto onde ocorre. No que se refere à dimensão temporal da pesquisa, esta tem corte transversal.

A unidade de análise deste trabalho consiste nas competências de uma cadeia de suprimentos localizada no município de Gravataí no estado do Rio Grande do Sul e atuante no setor automobilístico. A empresa focal da cadeia de suprimentos analisada está entre as maiores montadoras automotivas existentes no mundo. Foi fundada em 1908 em Detroit e emprega aproximadamente 235.000 funcionários em todo o mundo, produzindo veículos em 34 países. No Brasil, a montadora atua desde 1925 onde se instalou na cidade de São Paulo. Atualmente possui quatro complexos industriais. O primeiro complexo situa-se em São Caetano do Sul (SP), o segundo em São José dos Campos (SP), o complexo industrial e comercial de Mogi das Cruzes, na Região da Grande São Paulo é o terceiro complexo industrial. Em 20 de julho de 2000, foi inaugurado o quarto complexo industrial localizado em Gravataí no Estado do Rio Grande do Sul. Dispõe de 386 hectares e área construída de $140.000 \mathrm{~m} 2$.

Esta cadeia iniciou efetivamente suas atividades no ano de $2000 \mathrm{com} o$ propósito de produzir um veículo pequeno, popular, moderno e com preço competitivo. A escolha deste caso justifica-se por três motivos: (a) a possibilidade de estudar uma cadeia de suprimentos instalada dentro de um condomínio industrial que opera com um desempenho considerado notório pela matriz americana, (b) a complexa criticidade de operações, tempos e movimentos, das empresas fornecedoras para o efetivo atendimento da cadeia de suprimentos e (c) a acessibilidade às informações. 
Esta pesquisa foi realizada através do estabelecimento de 5 fases apresentadas a seguir. A fase 1 refere-se à sustentação teórica que tem por finalidade embasar o desenvolvimento do estudo dando subsídios teóricos para responder à questão problema que norteia a pesquisa. A revisão de conteúdos possibilitou a definição das categorias iniciais de análise para a identificação das competências da cadeia de suprimentos, conforme o Quadro 2.

\begin{tabular}{|c|c|c|}
\hline Eixo Crítico & Categorias Iniciais de Análise & Sustentação Teórica \\
\hline \multirow{5}{*}{$\begin{array}{l}\text { Relacionamento } \\
\text { com a cadeia }\end{array}$} & Relacionamento com fornecedores & \multirow{5}{*}{$\begin{array}{l}\text { Lummus e Vokurska (1999) } \\
\text { Davis et al. (2001) } \\
\text { Lambert (2004) } \\
\text { Eng (2006) } \\
\text { Vieira et al (2009) }\end{array}$} \\
\hline & $\begin{array}{l}\text { Compartilhamento de riscos } \mathrm{e} \\
\text { benefícios }\end{array}$ & \\
\hline & Confiança & \\
\hline & Ações conjuntas & \\
\hline & Cultura participativa & \\
\hline \multirow{4}{*}{$\begin{array}{l}\text { Gestão da } \\
\text { Informação }\end{array}$} & Compartilhamento de informações & \multirow{4}{*}{$\begin{array}{l}\text { Lummus e Vokurska(1999) } \\
\text { Davis et al. (2001), Chopra } \\
\text { e Meindl (2003), Lambert } \\
\text { (2004), Eng (2006), Vieira } \\
\text { et al. (2009) }\end{array}$} \\
\hline & Confiabilidade no compartilhamento & \\
\hline & $\begin{array}{l}\text { Integração de processos e } \\
\text { procedimentos }\end{array}$ & \\
\hline & Tecnologia da informação & \\
\hline \multirow{5}{*}{$\begin{array}{l}\text { Relacionamento } \\
\text { com o Cliente }\end{array}$} & Relacionamento com clientes, CRM & \multirow{5}{*}{$\begin{array}{l}\text { Christopher (1997) } \\
\text { Davis et al. (2001) } \\
\text { Lambert (2004) }\end{array}$} \\
\hline & Retenção e fidelidade de clientes & \\
\hline & Serviços disponíveis & \\
\hline & Confiança & \\
\hline & Desenvolvimento de novos produtos & \\
\hline \multirow{4}{*}{$\begin{array}{l}\text { Gestão de } \\
\text { Materiais }\end{array}$} & Relacionamento com fornecedores & \multirow{4}{*}{$\begin{array}{l}\text { Lummus e Vokurka (1999) } \\
\text { Chopra e Meindl (2003) } \\
\text { Vieira et al. (2009) }\end{array}$} \\
\hline & Administração de Estoques & \\
\hline & Transporte e distribuição & \\
\hline & Armazenagem & \\
\hline
\end{tabular}

A fase 2 consistiu em caracterizar a cadeia de suprimentos e compreender sua visão acerca dos eixos críticos bem como identificar suas competências relacionadas aos eixos críticos desenvolvidos para a pesquisa. Nesta fase foram entrevistados dois responsáveis pela empresa focal da cadeia. Estes profissionais detêm o conhecimento dos processos e procedimentos da cadeia como um todo. Durante a entrevista, para colaborar com a identificação dos elementos constitutivos e das competências, foram utilizados como alicerce os quatro eixos críticos desenvolvidos para a pesquisa. Durante a entrevista, cada um dos eixos críticos foi apresentado aos entrevistados e posteriormente desmembrado em uma competência organizacional. Foram identificadas ao todo, quatro competências organizacionais da cadeia de suprimentos, uma para cada eixo. As quatro competências identificadas procuraram abarcar todos os elementos constitutivos verbalizados pelos entrevistados.

$\mathrm{Na}$ fase 3 foram definidos os parâmetros para compor os níveis de agregação de valor das competências, tendo como base a revisão teórica desenvolvida na fase 1 e as informações colhidas na fase 2 da pesquisa.

A fase 4 consistiu em identificar em que níveis de agregação de valor encontram-se as empresas fornecedoras pesquisadas em relação às competências da cadeia de suprimentos. Nesta fase foram entrevistados oito gestores das 
empresas fornecedoras, indicados pela empresa focal da cadeia de suprimentos. Os pesquisadores sugeriram a indicação de quatro fornecedores sistemistas instalados dentro do condomínio industrial e quatro fornecedores externos, instalados fora do condomínio industrial. O propósito de investigar fornecedores de dentro e de fora do condomínio foi verificar se existem níveis diferentes de contribuição nas competências da cadeia de suprimentos conforme o grupo de fornecedores pesquisado. As características destes fornecedores estão representados no Quadro 3.

\begin{tabular}{|c|c|c|c|c|c|}
\hline $\begin{array}{l}\text { Códig } \\
0\end{array}$ & $\begin{array}{c}\text { Cargo do } \\
\text { Entrevistado }\end{array}$ & Localização & $\begin{array}{l}\text { Temp } \\
\text { o de } \\
\text { Forne- } \\
\text { cimen } \\
\text { to }\end{array}$ & $\begin{array}{l}\text { Representativid } \\
\text { ade do } \\
\text { fornecimento } \\
\text { para a cadeia no } \\
\text { faturamento }\end{array}$ & $\begin{array}{c}\dot{E} \\
\text { fornece } \\
\text {-dora } \\
\text { de } \\
\text { outras } \\
\text { cadeias } \\
?\end{array}$ \\
\hline FS 1 & $\begin{array}{l}\text { Gerente de } \\
\text { Manufatura }\end{array}$ & Gravataí/RS & $\begin{array}{c}10 \\
\text { anos }\end{array}$ & $100 \%$ & Não \\
\hline FS 2 & $\begin{array}{l}\text { Gerente de } \\
\text { Fábrica }\end{array}$ & Gravataí/RS & 2 anos & $100 \%$ & Não \\
\hline FS 3 & $\begin{array}{l}\text { Gerente de } \\
\text { Fábrica }\end{array}$ & Gravataí/RS & 4 anos & $100 \%$ & Não \\
\hline FS 4 & $\begin{array}{l}\text { Gerente de } \\
\text { Planta }\end{array}$ & Gravataí/RS & $\begin{array}{c}10 \\
\text { anos }\end{array}$ & $100 \%$ & Não \\
\hline FE 1 & $\begin{array}{l}\text { Gerente de } \\
\text { Logística }\end{array}$ & $\begin{array}{c}\text { São } \\
\text { Leopoldo/RS }\end{array}$ & 1 ano & $90 \%$ & Sim \\
\hline FE 2 & $\begin{array}{c}\text { Diretor Supply } \\
\text { Chain }\end{array}$ & $\begin{array}{c}\text { Porto } \\
\text { Alegre/RS }\end{array}$ & $\begin{array}{c}10 \\
\text { anos }\end{array}$ & $5 \%$ & Sim \\
\hline FE 3 & $\begin{array}{l}\text { Gerente de } \\
\text { Fábrica }\end{array}$ & $\begin{array}{c}\text { Porto } \\
\text { Alegre/RS }\end{array}$ & $\begin{array}{c}10 \\
\text { anos }\end{array}$ & 90 & Sim \\
\hline FE 4 & $\begin{array}{l}\text { Analista de } \\
\text { Logística }\end{array}$ & $\begin{array}{c}\text { Porto } \\
\text { Alegre/RS }\end{array}$ & $\begin{array}{c}10 \\
\text { anos }\end{array}$ & $20 \%$ & Sim \\
\hline
\end{tabular}

Quadro 3 - Características dos fornecedores pesquisados Fonte: Elaborado pelos autores

É importante ressaltar, que para os fins desta pesquisa, as oito empresas fornecedoras foram divididas em dois grupos. No primeiro grupo estão as quatro empresas fornecedoras sistemistas (FS $\mathrm{x}$ ). As sistemistas são aquelas que geralmente estão localizadas dentro do condomínio industrial e que, conforme Amato Neto e D'Angelo (2005), assumem a responsabilidade de atuar conjuntamente no controle de custos e na prestação de serviços, fornecem toda a sua produção para a montadora cumprindo rigorosamente o prazo e a seqüência requerida e são responsáveis pelo fornecimento de um módulo completo do veículo. Já no segundo grupo estão às quatro empresas fornecedoras externas ( $F E x)$, aquelas que não estão instaladas dentro do condomínio industrial, localizando-se em municípios próximos. Estas não possuem atuação direta no controle de custos e serviços da cadeia, sua produção geralmente é fornecida para montadoras distintas e fornecem um importante componente do veículo. Destaca-se que tanto as empresas fornecedoras sistemistas quanto as empresas fornecedoras externas são consideradas fornecedoras de primeiro nível, aquelas que conforme Lambert e 
Cooper (2000) fornecem módulos ou componentes diretamente para a empresa focal da cadeia de suprimentos.

A fase 5 teve como finalidade analisar os resultados obtidos. Para isto, foram detalhados os resultados obtidos na fase 4 e apresentado o nível de contribuição das empresas fornecedoras, sob a perspectiva dos níveis de agregação de valor, nas competências da cadeia de suprimentos.

\section{Identificação das competências tendo como base os eixos críticos}

$\mathrm{Na}$ identificação das quatro competências foram utilizadas as seguintes fontes de dados: (a) a pesquisa teórica sobre competências; (b) a formação dos quatro eixos críticos fundamentados no referencial teórico sobre Fatores Críticos de Sucesso para as cadeias de suprimentos; (c) as entrevistas com dois gestores da empresa focal da cadeia de suprimentos; (d) os elementos constitutivos identificados e validados pelos gestores da empresa focal para cada competência. Estes elementos constitutivos que compõem cada uma das competências foram identificados através da entrevista com os gestores da empresa focal e contribuem para tornar claro a composição e o contexto de cada uma. A seguir apresentam-se os eixos críticos e a definição de cada competência associada a estes eixos.

1) Eixo Crítico Relacionamento com a Cadeia - Competência Cultura Participativa e Confiável: É a capacidade da cadeia de suprimentos manter uma cultura participativa e confiável, oportunizando o desenvolvimento de ações coletivas que beneficiem as empresas atuantes da cadeia frente aos concorrentes do mesmo segmento.

2) Eixo Crítico Gestão da Informação - Competência Velocidade e Credibilidade das Informações: É a capacidade da cadeia de suprimentos em compartilhar com velocidade e credibilidade as informações necessárias para a tomada de decisão em todos os níveis da cadeia.

3) Eixo Crítico Relacionamento com o Cliente - Competência Cumprimento de Prazos com Integridade: É a capacidade da cadeia de suprimentos em cumprir os prazos de entrega do produto final com integridade, garantindo $o$ abastecimento no ponto de vendas e estreitando o canal de relacionamento com a concessionária.

4) Eixo Crítico Gestão de Materiais - Competência Níveis de Estoques Reduzidos: É a capacidade da cadeia de suprimentos em manter níveis de estoques reduzidos, incentivando o aprimoramento da capacidade técnica dos fornecedores e gerenciando o trânsito, os custos e os giros dos materiais.

\section{Definição dos níveis de agregação de valor das competências}

Após a identificação das competências com base nos eixos críticos, torna-se necessário definir com clareza os critérios de diferenciação para identificar os níveis de agregação de valor de cada competência. Para a definição destes níveis, caracterizou-se cada um dos eixos críticos conforme proposta de Vinhas (2008), ilustrado a seguir na Figura 1. As dimensões propostas para definir os níveis de 
agregação de valor são: (a) Nível de complexidade, (b) Nível de atuação, (c) Abrangência de atuação, (d) Escopo de Responsabilidade, (e) Nível da estruturação das atividades, (f) Tratamento da Informação e (g) Autonomia e grau de supervisão. Os critérios de diferenciação foram identificados a partir da revisão teórica e das entrevistas com os gestores da empresa focal da cadeia de suprimentos, realizadas na fase 2.

Figura 1 - Níveis de agregação de valor das competências da cadeia de suprimentos

\begin{tabular}{|c|c|c|}
\hline & Cultura Participativa e Confiável & $\begin{array}{l}\text { Velocidade e Credibilidade das } \\
\text { Informações }\end{array}$ \\
\hline Nível & Agregação de Valor & Agregação de Valor \\
\hline 5 & $\begin{array}{l}\text { Definição de ações estratégicas no } \\
\text { planejamento e desenvolvimento de } \\
\text { projetos para implantar uma cultura } \\
\text { participativa entre cadeias de } \\
\text { suprimentos nacionais e internacionais, } \\
\text { decidindo e proporcionando o consenso } \\
\text { das decisões }\end{array}$ & $\begin{array}{l}\text { Coordenação de projetos de } \\
\text { intercâmbio de informações entre } \\
\text { cadeia de suprimentos nacionais e } \\
\text { internacionais, com o propósito de } \\
\text { buscar e implantar novas tecnologias } \\
\text { para melhorar o desempenho }\end{array}$ \\
\hline 4 & $\begin{array}{l}\text { Supervisão no desenvolvimento de } \\
\text { projetos entre cadeia de suprimentos } \\
\text { nacionais, buscando o senso comum } \\
\text { entre os atuantes e delineando novas } \\
\text { tendências para instaurar a cultura } \\
\text { participativa }\end{array}$ & $\begin{array}{l}\text { Supervisão no desenvolvimento de } \\
\text { projetos entre cadeia de suprimentos } \\
\text { nacionais, através da análise de } \\
\text { mecanismos que facilite o acesso às } \\
\text { informações. }\end{array}$ \\
\hline 3 & $\begin{array}{l}\text { Atuação em projetos de melhoria } \\
\text { contínua, estimulando a sinergia, a } \\
\text { participação e a integração da cadeia } \\
\text { de suprimentos e proporcionando o } \\
\text { estabelecimento de diretrizes para } \\
\text { manter a cultura participativa }\end{array}$ & $\begin{array}{llr}\text { Atuação no estabelecimento de } \\
\text { diretrizes para o follow-up de pedidos } \\
\text { e entregas da cadeia de } \\
\text { suprimentos, } \quad \text { monitorando a } \\
\text { velocidade e credibilidade das } \\
\text { informações recebidas }\end{array}$ \\
\hline 2 & $\begin{array}{l}\text { Articulação e apresentação de novos } \\
\text { assuntos para as reuniões periódicas da } \\
\text { cadeia de suprimentos, focados em } \\
\text { ações de melhoria contínua que } \\
\text { beneficiem o relacionamento da cadeia } \\
\text { de suprimentos. }\end{array}$ & $\begin{array}{l}\text { Articulação e apresentação de novos } \\
\text { assuntos para as reuniões periódicas } \\
\text { da cadeia de suprimentos, propondo } \\
\text { melhorias para aperfeiçoar a } \\
\text { comunicação e o fluxo de } \\
\text { informações. }\end{array}$ \\
\hline \multirow[t]{2}{*}{1} & $\begin{array}{l}\text { Participação nas reuniões periódicas da } \\
\text { cadeia de suprimentos através da troca } \\
\text { de informações sobre assuntos } \\
\text { discutidos. }\end{array}$ & $\begin{array}{l}\text { Participação nas reuniões periódicas } \\
\text { da cadeia de suprimentos, } \\
\text { viabilizando a troca de informações } \\
\text { via edi. }\end{array}$ \\
\hline & $\begin{array}{l}\text { Cumprimento de Prazos com } \\
\text { Integridade }\end{array}$ & Níveis de Estoques Reduzidos \\
\hline Nível & Agregação de Valor & Agregação de Valor \\
\hline 5 & $\begin{array}{l}\text { Coordenação de projetos entre cadeia } \\
\text { de suprimentos nacionais e } \\
\text { internacionais, com o propósito de } \\
\text { decidir e definir demandas e atividades } \\
\text { para ofertar novos produtos ao mercado } \\
\text { consumidor. }\end{array}$ & $\begin{array}{l}\text { Coordenação de projetos } \\
\text { estratégicos entre cadeias nacionais } \\
\text { e internacionais, para delinear ações } \\
\text { de redução de custos e perdas com } \\
\text { materiais e embalagens, } \\
\text { recomendando propostas de } \\
\text { melhorias. }\end{array}$ \\
\hline
\end{tabular}




\begin{tabular}{|c|c|c|}
\hline 4 & $\begin{array}{l}\text { Supervisão e análise de projetos entre } \\
\text { cadeia de suprimentos nacionais, para } \\
\text { delinear as tendências mercadológicas } \\
\text { e analisar propostas que atendam as } \\
\text { necessidades do segmento de atuação. }\end{array}$ & $\begin{array}{l}\text { Supervisão em projetos de } \\
\text { desenvolvimento da capacidade } \\
\text { produtiva e técnica de fornecedores } \\
\text { em nível nacional, decidindo por } \\
\text { soluções que elevem o nível de } \\
\text { confiabilidade na entrega. }\end{array}$ \\
\hline 3 & $\begin{array}{l}\text { Análise e estruturação dos dados } \\
\text { oriundos das concessionárias e dos } \\
\text { eventos com os conselheiros do } \\
\text { veículo, sobre defeitos, reclamações e } \\
\text { expectativas, com o propósito de } \\
\text { estabelecer diretrizes e definir ações } \\
\text { para ajustar a qualidade final do } \\
\text { produto. }\end{array}$ & $\begin{array}{l}\text { Estabelecimento e estruturação de } \\
\text { diretrizes para sinalizar imprevistos } \\
\text { no abastecimento de materiais e } \\
\text { embalagens na cadeia de } \\
\text { suprimentos, analisando dados } \\
\text { históricos de problemas já ocorridos. }\end{array}$ \\
\hline 2 & $\begin{array}{l}\text { Consolidação e organização das } \\
\text { informações para o cumprimento do } \\
\text { plano de produção/vendas, estruturando } \\
\text { as necessidades para o atendimento } \\
\text { dos prazos de entrega. }\end{array}$ & $\begin{array}{l}\text { Consolidação e organização dos } \\
\text { tempos de trânsito dos materiais e } \\
\text { embalagens propondo das reuniões } \\
\text { periódicas da cadeia de suprimentos, } \\
\text { ganhos de tempos e movimentos. }\end{array}$ \\
\hline 1 & $\begin{array}{l}\text { Participação nas reuniões periódicas da } \\
\text { cadeia de suprimentos, com o propósito } \\
\text { de tomar ciência do plano de } \\
\text { produção/vendas e receber os dados } \\
\text { sobre defeitos e reclamações das } \\
\text { concessionárias. }\end{array}$ & $\begin{array}{l}\text { Participação nas reuniões periódicas } \\
\text { da cadeia de suprimentos } \\
\text { viabilizando o monitoramento do giro } \\
\text { dos materiais e o controle dos itens } \\
\text { de valor agregado. }\end{array}$ \\
\hline
\end{tabular}

Fonte: Elaborado pelos autores

\section{Identificação dos níveis de agregação de valor dos fornecedores em relação às competências da cadeia}

Para que fosse possível determinar a contribuição dos fornecedores na agregação de valor das competências da cadeia de suprimentos, cada um dos oito fornecedores pesquisados foi entrevistado individualmente para que se posicionasse em relação ao nível de agregação de valor das competências.

Os quadros a seguir apresentam as competências da cadeia de suprimentos e a indicação dos níveis de agregação de valor de cada um dos fornecedores pesquisados. Cabe salientar que o nível 3 de agregação de valor na competência é considerado satisfatório, uma vez que representa uma contribuição que atende aos padrões estabelecidos pela cadeia, evidenciando uma atuação ativa da empresa na cadeia em que faz parte. Já os níveis 1 e 2 representam um nível básico de contribuição. As empresas com estes níveis de contribuição estão aquém do esperado pela cadeia de suprimentos. O fornecedor que atuar no nível 4 estará superando as expectativas, visto que esta contribuição ultrapassa as fronteiras da cadeia em que atua. Neste nível, existe o relacionamento das empresas fornecedoras com outras cadeias de suprimentos em nível nacional. Por fim, o nível 5 é considerado como excepcional, pois contribuir neste estágio significa relacionarse com as cadeias de suprimentos nacionais e também internacionais. 
Em relação à competência Cultura Participativa e Confiável, observa-se no Quadro 4 que os fornecedores FS1 e FE1, um fornecedor sistemista localizado dentro do condomínio industrial, e um fornecedor externo, estão no nível 1, demonstrando que contribuem com o requisito básico desta competência. $O$ nível 1 evidencia a participação nas reuniões periódicas da cadeia através da troca de informações sobre os assuntos discutidos.Observa-se também que fornecedores FS2, FS3, FS4, FE2, FE3 e FE4, três fornecedores sistemistas e três fornecedores externos contribuem no nível 3 . O nível 3 evidencia a atuação em projetos de melhoria contínua, estimulando a sinergia, a participação e a integração da cadeia de suprimentos e proporcionando o estabelecimento de diretrizes para manter a cultura participativa. Destaca-se que nenhum fornecedor contribui nos níveis 4 ou 5 , demonstrando que não apresentam relacionamentos com outras cadeias de nível nacional e internacional.

Quanto à competência Velocidade e Credibilidade das Informações, observa-se no Quadro 5 que o fornecedor FE1, fornecedor externo, encontra-se no nível 1, o nível básico. Isto demonstra que tal fornecedor contribui com o mínimo de valor agregado para a cadeia, ou seja, participa das reuniões periódicas da cadeia de suprimentos e viabiliza a troca de informações via EDI. Por outro lado, verifica-se que todos os demais fornecedores, tanto sistemistas quanto externos, atuam no nível 3 em relação a essa competência.

\begin{tabular}{|c|c|c|c|c|c|c|c|c|}
\hline \multirow{2}{*}{$\begin{array}{c}\text { Competência } \\
\text { da Cadeia }\end{array}$} & \multicolumn{6}{|c|}{$\begin{array}{l}\text { Eixo Crítico Relacionamento com a Cadeia } \\
\text { da cadeia de suprimentos manter uma cultura participativa e } \\
\text { confiável, oportunizando o desenvolvimento de ações coletivas } \\
\text { que beneficiem as empresas atuantes da cadeia frente aos } \\
\text { concorrentes do mesmo segmento. }\end{array}$} \\
\hline $\begin{array}{c}\text { Nível de } \\
\text { agregação de } \\
\text { valor }\end{array}$ & FS1 & FS2 & FS3 & FS4 & FE1 & FE2 & FE3 & FE4 \\
\hline 5 & & & & & & & & \\
\hline 4 & & & & & & & & \\
\hline 3 & & $\mathrm{X}$ & $\mathrm{X}$ & $\mathrm{X}$ & & $\mathrm{X}$ & $\mathrm{X}$ & $\mathrm{X}$ \\
\hline $\mathbf{2}$ & & & & & & & & \\
\hline 1 & $\mathrm{X}$ & & & & $\mathrm{X}$ & & & \\
\hline
\end{tabular}

Quadro 4 - Agregação de valor dos fornecedores na competência Cultura Participativa e Confiável

Fonte: Elaborado pelos autores

Contribuir no terceiro nível significa atuar no estabelecimento de diretrizes para o follow-up de pedidos e entregas da cadeia de suprimentos, monitorando a velocidade e credibilidade das informações recebidas. Destaca-se que nenhum fornecedor contribui nos níveis 4 e 5, visto que estes níveis pressupõe as empresas fornecedores ultrapassarem as fronteiras da cadeia em que atuam, passando a estabelecerem relacionamentos com outras cadeias de suprimentos em nível nacional e internacional. 


\begin{tabular}{|c|c|c|c|c|c|c|c|c|}
\hline \multirow{2}{*}{$\begin{array}{c}\text { Competência } \\
\text { da Cadeia }\end{array}$} & \multicolumn{6}{|c|}{ Eixo Crítico Gestão da Informação } \\
\cline { 2 - 9 } & \multicolumn{6}{|c|}{$\begin{array}{l}\text { Competência Velocidade e Credibilidade das Informações: É a } \\
\text { capacidade da cadeia de suprimentos em compartilhar com } \\
\text { velocidade e credibilidade as informações necessárias para a } \\
\text { tomada de decisão em todos os níveis da cadeia. }\end{array}$} \\
\hline $\begin{array}{c}\text { Nível de } \\
\text { agregação } \\
\text { de valor }\end{array}$ & FS1 & FS2 & FS3 & FS4 & FE1 & FE2 & FE3 & FE4 \\
\hline 5 & & & & & & & & \\
\hline 4 & & & & & & & & \\
\hline 3 & $\mathrm{X}$ & $\mathrm{X}$ & $\mathrm{X}$ & $\mathrm{X}$ & & $\mathrm{X}$ & $\mathrm{X}$ & $\mathrm{X}$ \\
\hline $\mathbf{2}$ & & & & & & & & \\
\hline 1 & & & & & $\mathrm{X}$ & & & \\
\hline
\end{tabular}

Quadro 5 - Agregação de valor dos fornecedores na competência Velocidade e Credibilidade das Informações

Fonte: Elaborado pelos autores

Na competência Cumprimento de Prazos com Integridade, observa-se no Quadro 6 que um fornecedor está no nível 3 e os demais estão no nível 2.

O fornecedor FS2 analisa e estrutura os dados oriundos das concessionárias e dos eventos com os conselheiros do veículo sobre defeitos, reclamações e expectativas, com o propósito de estabelecer diretrizes e definir ações para ajustar a qualidade final do produto. Os demais fornecedores, localizados no nível 2, consolidam e organizam as informações para o cumprimento do plano de produção/vendas, estruturando as necessidades para o atendimento dos prazos de entrega. Destaca-se que este nível é considerado como um nível básico, pois a contribuição está no atendimento do plano de produção/vendas, o que é considerado como essencial para a cadeia de suprimentos.

\begin{tabular}{|c|c|c|c|c|c|c|c|c|}
\hline \multirow{2}{*}{$\begin{array}{c}\text { Competência } \\
\text { da Cadeia }\end{array}$} & \multicolumn{6}{|c|}{$\begin{array}{l}\text { Eixo Crítico Relacionamento com o Cliente } \\
\text { capacidade da cadeia de suprimentos em cumprir os prazos de } \\
\text { entrega do produto final com integridade, garantindo o } \\
\text { abastecimento no ponto de vendas e estreitando o canal de } \\
\text { relacionamento com a concessionária. }\end{array}$} \\
\hline $\begin{array}{c}\text { Nível de } \\
\text { agregação } \\
\text { de valor }\end{array}$ & FS1 & FS2 & FS3 & FS4 & FE1 & FE2 & FE3 & FE4 \\
\hline 5 & & & & & & & & \\
\hline 4 & & & & & & & & \\
\hline 3 & & $\mathrm{X}$ & & & & & & \\
\hline 2 & $\mathrm{X}$ & & $\mathrm{X}$ & $\mathrm{X}$ & $\mathrm{X}$ & $\mathrm{X}$ & $\mathrm{X}$ & $\mathrm{X}$ \\
\hline 1 & & & & & & & & \\
\hline
\end{tabular}

Quadro 6: Agregação de valor dos fornecedores na competência Cumprimento de Prazos com Integridade

Fonte: Elaborado pelos autores. 
Salienta-se que em relação a esta competência, pelas entrevistas realizadas, é percebido que a maioria dos fornecedores pode elevar no mínimo mais um nível a sua contribuição, considerado como satisfatório pela cadeia. Destaca-se também que nenhum fornecedor contribui no nível 4 nem no nível 5 , pois tais níveis significam relacionar-se com as cadeias de suprimentos nacionais e também internacionais coordenando projetos com o propósito de decidir e definir as demandas e atividades para ofertar novos produtos ao mercado consumidor.

Na competência Níveis de Estoques Reduzidos, o Quadro 7 mostra que as empresas fornecedoras contribuem de forma diversa.

\begin{tabular}{|c|c|c|c|c|c|c|c|c|}
\hline \multirow{2}{*}{$\begin{array}{c}\text { Competência } \\
\text { da Cadeia }\end{array}$} & \multicolumn{6}{|c|}{$\begin{array}{l}\text { Cixo Crítico Gestão de Materiais } \\
\text { cadeia de suprimentos em manter níveis de estoques reduzidos, } \\
\text { incentivando o aprimoramento da capacidade técnica dos } \\
\text { fornecedores e gerenciando o trânsito, os custos e os giros dos } \\
\text { materiais. }\end{array}$} \\
\hline $\begin{array}{c}\text { Nível de } \\
\text { agregação } \\
\text { de valor }\end{array}$ & FS1 & FS2 & FS3 & FS4 & FE1 & FE2 & FE3 & FE4 \\
\hline 5 & & & & & & & & \\
\hline 4 & & $\mathrm{X}$ & & & & & & \\
\hline 3 & & & $\mathrm{X}$ & $\mathrm{X}$ & & $\mathrm{X}$ & $\mathrm{X}$ & $\mathrm{X}$ \\
\hline $\mathbf{2}$ & & & & & & & & \\
\hline 1 & $\mathrm{X}$ & & & & $\mathrm{X}$ & & & \\
\hline
\end{tabular}

Quadro 7: Agregação de valor dos fornecedores na competência Níveis de Estoques Reduzidos Fonte: Elaborado pelos autores.

Para a agregação de valor da competência Níveis de Estoques Reduzidos, têm-se dois fornecedores no primeiro nível, cinco fornecedores no terceiro nível e um fornecedor no nível quatro. Os fornecedores FS1 e FE1 contribuem no primeiro nível onde participam nas reuniões periódicas da cadeia de suprimentos, viabilizando o monitoramento do giro dos materiais e o controle dos itens de valor agregado. Em relação aos fornecedores FS3, FS4, FE2, FE3 e FE4, os mesmos contribuem no terceiro nível de agregação de valor da competência. Este nível atende satisfatoriamente às expectativas da cadeia. Evidencia-se tal condição pelo estabelecimento e estruturação de diretrizes para sinalizar imprevistos no abastecimento de materiais e embalagens na cadeia de suprimentos, analisando dados históricos de problemas já ocorridos. O fornecedor FS2 contribui no quarto nível de agregação de valor, o que significa supervisionar projetos de desenvolvimento da capacidade produtiva e técnica de fornecedores em nível nacional, decidindo por soluções que elevem o nível de confiabilidade na entrega. A contribuição neste estágio supera as expectativas, visto que este fornecedor relaciona-se com outras cadeias de suprimentos em nível nacional, objetivando buscar ganhos para a cadeia em que efetivamente atua. Observa-se que para a competência Níveis de Estoques Reduzidos nenhum fornecedor apresenta-se no nível 5. Destaca-se que este nível é considerado como excepcional, pois contribuir neste estágio significa coordenar projetos estratégicos entre cadeias nacionais e internacionais, para delinear ações de redução de custos e perdas com materiais e embalagens, recomendando propostas de melhoria. 
A seção seguinte abordará uma análise das contribuições dos fornecedores pesquisados na agregação de valor das competências da cadeia de suprimentos.

\section{Análise dos níveis de agregação de valor dos fornecedores nas competências da cadeia}

Um dos primeiros pontos de análise refere-se às ligações de processos propostos por Lambert e Cooper (2000). Para estes autores a estrutura de uma cadeia de suprimentos pode apresentar ligações de processos gerenciados, monitorados, não gerenciados e não membros. Observa-se que para a cadeia de suprimentos analisada, estas ligações estão presentes, entre a empresa focal e seus fornecedores.

As ligações de processos gerenciados, aqueles considerados críticos pela empresa focal, são realizadas com os fornecedores externos, localizados fora do condomínio industrial. Para a empresa focal, os fornecedores externos são os de menor convívio diário, que não dispõem dos benefícios de estar dentro do condomínio e que possuem um suporte inferior por parte da cadeia, portanto é importante integrá-los e estar ativamente envolvida na gestão dos mesmos.

As ligações de processos monitorados são aquelas que a empresa focal, tão freqüentemente quanto necessário, monitora ou audita seus processos. Neste sentido, os fornecedores sistemistas são considerados empresas com processos monitorados, pois possuem um convívio diário com a empresa focal, partilhando freqüentemente ações para a solução de problemas. Para se tornarem sistemistas, estes fornecedores foram submetidos a uma extensa avaliação de seus processos.

Com o intuito de relembrar os diferentes níveis de agregação de valor dos fornecedores em relação às competências, apresenta-se o Quadro $8 \mathrm{com}$ as quatro competências e o nível de agregação de valor de cada fornecedor pesquisado.

\begin{tabular}{|c|c|c|c|c|c|c|c|c|}
\hline \multirow{2}{*}{ Competência da Cadeia } & \multicolumn{6}{|c|}{ Nível de Agregação de Valor } \\
\cline { 2 - 9 } & \multicolumn{4}{|c|}{$\begin{array}{c}\text { Fornecedores } \\
\text { Sistemistas }\end{array}$} & \multicolumn{4}{c|}{$\begin{array}{c}\text { Fornecedores } \\
\text { Externos }\end{array}$} \\
\cline { 2 - 10 } & FS1 & FS2 & FS3 & FS4 & FE1 & FE2 & FE3 & FE4 \\
\hline Cultura Participativa e Confiável & 1 & 3 & 3 & 3 & 1 & 3 & 3 & 3 \\
\hline $\begin{array}{c}\text { Velocidade e Credibilidade das } \\
\text { Informações }\end{array}$ & 3 & 3 & 3 & 3 & 1 & 3 & 3 & 3 \\
\hline $\begin{array}{c}\text { Cumprimento dos Prazos com } \\
\text { Integridade }\end{array}$ & 2 & 3 & 2 & 2 & 2 & 2 & 2 & 2 \\
\hline Níveis de Estoques Reduzidos & 1 & 4 & 3 & 3 & 1 & 3 & 3 & 3 \\
\hline
\end{tabular}

Quadro 8: Competências e níveis de agregação de valor dos fornecedores

Fonte: Elaborado pelos autores.

Em relação à competência Cultura Participativa e Confiável, destaca-se que esta competência vai ao encontro do que propõe Kanter (1994). A autora salienta que os relacionamentos entre empresas capazes de elevar a competitividade são baseados na integração estratégica, tática, operacional, interpessoal e cultural. Nesta competência foram observados estes cinco tipos de 
integração: a integração entre os gestores de alto escalão, gestores de nível médio, colaboradores, ações operacionais e culturais, capazes de oportunizar ações coletivas. Nesta competência, não foi identificada distinção de agregação de valor entre os fornecedores sistemistas e fornecedores externos, o que demonstra que a localização geográfica pode não interferir no nível de contribuição.

Em relação à competência Velocidade e Credibilidade das Informações, pode-se afirmar que esta visa reduzir as previsões de demandas distorcidas, os problemas na consistência dos prazos de entrega e os problemas de nãoconformidade dos produtos, eliminando fatos que podem gerar riscos para a cadeia de suprimentos (SILVA, LADEIRA \& OLIVEIRA, 2008). Destaca-se nesta competência que o fornecedor FE1 contribui no primeiro nível de agregação de valor. Este fornecedor fornece materiais para a cadeia há um ano, sendo o fornecedor mais novo entre todos os pesquisados. Assim, o curto tempo de fornecimento, pode ter influenciado sua contribuição, visto que o mesmo ainda está integrando-se com a funcionalidade da cadeia como um todo. Ainda com relação a esta competência, percebe-se não haver distinção de agregação de valor entre os fornecedores sistemistas e externos, pois todos contribuem no terceiro nível de agregação de valor desta competência, mostrando que a localização geográfica pode não interferir no nível de contribuição.

Em relação à competência Cumprimento de Prazos com Integridade, destaca-se novamente não haver distinção de agregação de valor entre os fornecedores sistemistas e os fornecedores externos, pois todos contribuem no segundo nível de agregação de valor na competência, sinalizando mais uma vez que a localização geográfica pode não interferir no nível de contribuição desta competência. Destaca-se também que o fornecedor FS2 contribui no terceiro nível de agregação de valor. Este fornecedor foi considerado pela empresa focal da cadeia como o principal sistemista do condomínio, por fornecer um componente complexo e de alto valor agregado. Sendo assim, o fator complexidade e valor agregado do componente fornecido, pode influenciar na contribuição da competência, visto que para fornecer um componente tecnicamente complexo e de alto valor, é necessário estar totalmente integrado e conhecer profundamente os dados sobre defeitos, reclamações e expectativas do cliente, objetivando ajustar a qualidade final do produto.

Em relação à competência Níveis de Estoques Reduzidos, destaca-se uma diversidade de contribuições, pois dois fornecedores encontram-se no primeiro nível, cinco fornecedores no terceiro e um fornecedor no quarto nível de agregação de valor da competência. Dos dois fornecedores que contribuem no primeiro nível, um é fornecedor sistemista e outro é fornecedor externo. Os cinco fornecedores que contribuem no terceiro nível de agregação de valor são dois fornecedores sistemistas e três fornecedores externos. Da mesma forma, como todos contribuem no terceiro nível, pode também não haver influência na contribuição desta competência o fato de estarem localizados dentro do condomínio industrial ou fora dele. O Fornecedor FS2 destaca-se na contribuição desta competência, estando no quarto nível de agregação de valor. Sendo um fornecedor de um componente complexo e de alto valor agregado, compromete-se com o desenvolvimento da capacidade produtiva e técnica, decidindo por soluções que elevem o nível de confiabilidade na entrega.

Para Amato Neto e D'Angelo (2005), os sistemistas possuem um relacionamento intenso com a empresa focal, devido ao fato de fornecerem um sistema completo do veículo e dividirem diversos custos do condomínio industrial. 
Para estes autores, os fornecedores sistemistas possuem uma participação mais efetiva, em relação aos fornecedores externos, nas atividades propostas pela empresa focal. Os resultados da pesquisa não evidenciaram a afirmação destes autores. Observa-se que não há uma diferenciação expressiva nos níveis de contribuição nas competências da cadeia entre os fornecedores sistemistas e os fornecedores externos, pois ambos contribuem em níveis semelhantes.

Tendo em vista o Quadro 8, observa-se que o nível de contribuição de um determinado fornecedor em uma competência específica tende a se repetir para as demais competências investigadas, não havendo uma diferença expressiva em relação ao nível de contribuição nas quatro competências investigadas. O nível de contribuição apresenta uma tendência a manter-se estável, não havendo variações com contribuições de maior ou menor intensidade. Isto pode ser explicado, pois os recursos disponíveis e a capacidade de explorá-los são os mesmos para todas as quatro competências pesquisadas.

Também se observa que, em sua grande maioria, os fornecedores pesquisados apresentam-se no terceiro nível de agregação de valor nas quatro competências analisadas. Este nível é considerado satisfatório, pois atende às demandas necessárias e representa uma atuação ativa na cadeia em que atuam.

É importante destacar que os níveis de contribuição 4 e 5 mostraram-se como sendo níveis excelentes e excepcionais. Para que os fornecedores possam contribuir no quarto e quinto nível de agregação de valor nas competências, é necessário transcender da cadeia local em que atuam e relacionar-se com outras cadeias de suprimentos em nível nacional e internacional. Compreende-se que, para contribuir nestes níveis de agregação de valor, se faz necessário um esforço intenso e contínuo, capaz de produzir os mais diversos benefícios na articulação de estratégias entre cadeias de suprimentos mundiais.

\section{Considerações finais}

A partir da revisão teórica sobre competências, níveis de agregação de valor e cadeias de suprimentos, e dos dados coletados e analisados, estabelecem-se conclusões que expressam os resultados desta pesquisa, tais como:

a) todos os fornecedores pesquisados contribuem para a agregação de valor das competências da cadeia de suprimentos que atuam;

b) a contribuição dos fornecedores pesquisados na agregação de valor das competências da cadeia de suprimentos ocorre em diferentes níveis de complexidade, porém não se evidenciou diferenças representativas nos níveis de agregação de valor nas competências da cadeia de suprimentos entre o grupo de fornecedores sistemistas e o grupo de fornecedores externos;

d) a localização dos fornecedores, tanto daqueles instalados dentro do condomínio industrial quanto dos instalados na capital gaúcha e região metropolitana, não influencia no nível de contribuição na agregação de valor das competências;

e) o nível de contribuição de um determinado fornecedor tende a repetir-se em todas as quatro competências analisadas;

f) o fator tempo de fornecimento para a cadeia de suprimentos pode influenciar no nível de contribuição na agregação de valor da competência; 
g) o fator complexidade técnica e valor do componente fornecido para a cadeia de suprimentos pode influenciar no nível de contribuição na agregação de valor da competência;

h) em sua grande maioria, os fornecedores pesquisados tendem a contribuir no terceiro nível de agregação das competências, sendo este nível considerado como intermediário;

i) em sua grande maioria, os fornecedores pesquisados não contribuem no quarto e quinto níveis, pois não transcendem da cadeia local em que atuam para relacionarem-se com outras cadeias de suprimentos a nível nacional e internacional.

j) A elevação do nível de contribuição dos fornecedores pode colaborar no fortalecimento das competências da cadeia de suprimentos.

A diferenciação de contribuição entre os oito fornecedores pesquisados acontece devido ao fato de alguns fornecedores possuírem recursos (físicos, humanos, financeiros) e deterem a capacidade de explorá-los, se comparados a outros fornecedores que não dispõem destas alternativas. Os fornecedores que detém e exploram estes recursos podem realizar atividades e propor alternativas capazes de elevar seus níveis de agregação de valor nas competências da cadeia de suprimentos.

Esta pesquisa procurou utilizar o rigor metodológico para alcançar um nível de confiabilidade e segurança nos resultados extraídos. Porém, devem ser consideradas e destacadas algumas limitações ocorridas no decorrer do trabalho. Uma limitação refere-se ao estudo de uma única cadeia de suprimentos. Entretanto, por ser uma cadeia consideravelmente representativa no seu meio, acredita-se em um grande potencial de generalização dos resultados. Também pode ser destacada como limitação da pesquisa a identificação de uma única competência para cada eixo crítico desenvolvido. Isto foi necessário devido ao extenso volume de informações que seriam geradas em relação ao tempo disponível para a conclusão da pesquisa.

Frente ao que foi exposto, acredita-se que este trabalho possibilitou a aplicabilidade dos conceitos de competências, níveis de agregação de valor e cadeias de suprimentos para o entendimento da contribuição dos fornecedores para o fortalecimento das competências da cadeia de suprimentos automotiva pesquisada.

Acredita-se que o trabalho permitirá um conhecimento da contribuição efetiva dos principais fornecedores nas competências da cadeia, proporcionando aos seus gestores uma visão mais clara e detalhada do potencial de crescimento de cada fornecedor pesquisado. Além disso, a identificação das competências organizacionais e o desenvolvimento dos níveis de agregação de valor possibilitarão uma maior atuação gerencial, tanto da empresa focal, quanto das empresas fornecedoras. Espera-se que, ao conhecer estas informações, a cadeia tenha mais subsídios para interferir nos processos relativos às competências organizacionais identificadas e aperfeiçoá-los, colaborando no desempenho organizacional da cadeia como um todo.

\section{Referências}

AMATO NETO, J.; D'ANGELO, F. The influence of automakers in industrial organization of auto parts companies: the case of the Brazilian automotive complex. 
In: International Conference on Industrial Engineering and Operations Management, Porto Alegre/RS, 2005.

BALLOU, R.; GILBERT, S. M.; MUKHERJEE, A. New Managerial Challenges from Supply Chain Opportunities. In: Industrial Marketing Management. v. 29, n. 1, p.7-18, jan. 2000.

BECKER, G. V. Trajetória de formação e desenvolvimento de competências organizacionais da Muri linhas de montagem. Tese de Doutorado em Administração, Universidade de São Paulo, São Paulo, Brasil, 2004.

CLEGG, S. R.; HARDY, C. Introdução: organização e estudos organizacionais. In: CLEGG, S. R.; HARDY, C.; NORD, W. R. (Org.). In: Handbook de estudos organizacionais. São Paulo: Atlas, 1998, 352p.

CHRISTOPHER, M. Logística e gerenciamento da cadeia de suprimentos. São Paulo, Atlas, 1997, 240p.

CHOPRA, S. MEINDL, P. Gerenciamento da cadeia de suprimentos: estratégia, planejamento e operação. São Paulo. Prentice Hall, 2003. 465p.

COX, A; SANDERSON, J.; WATSON, G. Supply Chains and Power Regimes: Toward an Analytic Framework for Managing Extended Networks of Buyer and Supplier Relationships. In: The Journal of Supply Chain Management, v. 37, n. 2, p. 28-35, Spring, 2001.

DAVIS, M. M.; AQUILANO, N. J.; CHASE, R. B. Fundamentos da Administração da Produção. Porto Alegre: Bookman, 2001. 598p.

DUBÉ, L.; PARÉ, G. Rigor in Information Systems Positivist Case Research: Current Practices, Trends and Recommendations, MIS Quaterly, v.27, n.4, p.597-635, December, 2003.

ENG, T. Y. An investigation into the mediating role of cross-functional coordination on the linkage between organizational norms and SCM performance. In: Industrial Marketing Management 35, p. 762-773, August, 2006.

FIGUEIREDO, P. N. Technological Learning and Competitive Performance. Chetenham, UK \& Northampton, USA: Edward Elgar, 2001. 214p.

FLEURY, A. C. C; FLEURY, M. T. L. Estratégias empresariais e formação de competências: um quebra-cabeça caleidoscópio da indústria brasileira. São Paulo: Atlas, 2000, 169p.

FURLANETTO, E. L. Formação das estruturas de coordenação nas cadeias de suprimentos: Estudos de caso em cinco empresas gaúchas. Tese de Doutorado em Administração. Universidade Federal do Rio Grande do Sul, Porto Alegre, RS, Brasil, 2002.

KANTER, R.M. Collaborative advantage: the art of alliances. Harvard Business Review, p. 96-108, Cambridge: July-Agu. 1994. 
LAMBERT, D. M.; COOPER, M. C.; PAGH, J. D. Supply chain management: implementation issues and research opportunities. In: The International Journal of Logistics Management. Florida, v. 9, n. 8, p. 1-19, 1998.

LAMBERT, D. M. The Eight Essential Supply Chain Management Processes. In: Supply Chain Management Review; ABI/INFORM Global, Sep. 2004.

LAMBERT, D. M.; COOPER, M. C. Issues in Supply Chain Management. Industrial Marketing Management, New York, n.29, p. 65-83, January, 2000.

LUMMUS, R. R.; VOKURKA, R. J. Defining supply chain management: a historical perspective and practical guidelines. Industrial Management \& Data Systems, MCB University Press, v1, p.11-17, 1999.

MILLS, J.; PLATTS, K.; BOURNE, M.; RICHARDS, H. Strategy and Performance: Competing Through Competences. Cambridge: University Press, 2002, 192.

PARKHE, A. Understanding trust in international alliances. Journal of World Business, v. 33, n. 3, p. 219-240, Autumn, 1998.

RUAS, R. Gestão das Competências Gerenciais e a Aprendizagem nas Organizações. Documento de estudo. EA/PPGA/UFRGS, 1999.

ROCKART, J. F. Chief executives define their own data needs, Harvard Business Review, v. 57, n. 2, p. 81-93, March-April, 1979.

SILVA, A. L. B.; LADEIRA, M. B.; OLIVEIRA, M. P. V. A aplicação do modelo de redes bayesianas para o Gerenciamento de risco de ruptura em cadeias de suprimento. XI Simpósio de Administração da Produção, Logística e Operações Internacionais. Local FGV-EAESP, de 27 à 29 de Agosto de 2008.

STIJNEN, D. A. J. M.; GRAAFF, R. P. M. de; ROEST, J. van der. Analysing the Veal Production Supply Chain: An Integrated Approach. In: ZIGGERS, G. W.; TRIENEKENS, J. H. \& ZUURBIER, P. J. P.; Proceedings of the Third International Conference on Chain Management in Agribusiness and the Food Industry. Wageningen, The Netherlands: Wageninigen Agricultural University - Management Studies Group, 28-29 May, 1998.

TEIXEIRA, R.; LACERDA, D. P. Gestão da Cadeia de Suprimentos: Análise dos Artigos Publicados em Alguns Periódicos Acadêmicos entre os Anos de 2004 e 2006. Gestão e Produção, São Carlos, v.17, n.1, p.1-14, jan./mar. 2010.

TORRES, N. A. Planejamento de informática na empresa. São Paulo, Atlas, 1989. $224 p$.

VIEIRA, J.; YOSHIZAKI, H.; HO, L. Collaboration intensity in the Brazilian supermarket retail chain. Supply Chain Management: An International Journal. v. 4, n. 1, p.11-21, January, 2009. 
VINHAS, A. P. L. C. A Contribuição das Empresas Associadas na Agregação de Valor das Competências de uma Rede de Cooperação Interorganizacional.

Dissertação Mestrado em Administração, Pontifícia Universidade Católica do Rio Grande do Sul, Porto Alegre, RS, Brasil, 2008.

ZARIFIAN, P. Objetivo Competência. São Paulo: Atlas, 2001, 197p. 